\title{
Maternal behavior as a risk factor for growth and development retardation in infant and toddlers up to 18 months
}

\author{
Ghada M.Khalil ${ }^{*}$ and Eman M. Salama ${ }^{2}$ \\ ${ }^{1}$ Public Health and Preventive Medicine, Faculty of Medicine, Zagazig University, Egypt \\ ${ }^{2}$ Family Medicine, Ministry of Health
}

*Corresponding author: GhadaMahmoudKhalil, E-mail: ghadamahmoud1@hotmail.com, Phone: 01062234831

\begin{abstract}
Background: early 18 months of life characterized by the most rapid growth and development and mainly affected by mother behavior and traits Objectives: to promote child development to improve the quality of life for our children in the future through assessment of child development in the first eighteen months of life, to identify factors affecting early childhood development. Subjects and Methods: cross section study takes infant from birth to 18 month, attending Family Unit at Kafr Mohamed Ismail, Fakous, Sharkia governorate. Sample size 140 infant, using structured growth and development sheet and structured mother's interview. Result: The study found that male children retardation were $13.2 \%$ and female children retardation were $15.3 \%$, artificially feed children were $100 \%$ retarded, low social class children were $100 \%$ retarded, children of illiterate mother $100 \%$ were retarded , Breast feeding, rapid response to child needs when crying, stimulating activities during feeding the child and giving different types of toys are factors having good impact on child development with significant difference. Conclusion: Program for early detection of developmental delay through screening of children attending PHC and family medicine units are important to assess development risk factor and Maternal stimulation for promoting early child development through better attachment and communication with infants.
\end{abstract}

Keywords: maternal behavior, growth retardation, infant, toddler, development.

\section{Introduction}

Growth and development, especially $1^{\text {st }}$ year of life depend mostly on affection, attention and stimulation in addition to good nutrition, proper health care and protection which all mainly given by mothers ${ }^{(\mathbf{1})}$.Motherhood practice affect infants starting form prenatal period through natal and post natal ${ }^{(2)}$.

Prenatal mother's factors include; genetics, exposure to teratogenes, maternal health, maternal nutrition, maternal emotions and stress, age of mother and mother education ${ }^{(3)}$. Natal mothers factors are affected by natal environment and health service provided to mother before, during and after delivery which give impact on neonatal health specially neonatal hypoxia, prematurity , and birth weight $^{(1)}$.

Postnatal mother's factors stress on mother's socioeconomic status, family structure which include both family size and type of family, number and order of siblings, home environment both cognitive and psychological , mothers perception and practice of play and mother's nutritional practice ${ }^{(4)}$.

Measuring motherhood practice directly is difficult but not impossible, family physician carries load of providing physical, social and psychological care for mothers and their infant through family context ${ }^{(5)}$. Also family physician hasa powerful tool to assess motherhood practice through prenatal to post natal period, mothers' practice watched and corrected by family physician pre and postnatal is a great opportunity for 
improvement of child growth and development (6).

Assessment of child growth and monitoring relay on valid and accurate tool mainly must include :anthropometric measurements(weight, length and head circumference), the infant growth index and plotting growth chart, development assessment simply by observation of developmental milestones and Denever developmental screening test which has four items ; personal and social, fine motor ,gross motor and language ${ }^{(7)}$.

Every year 200 million children under 5 years failed to reach their full cognitive and social potential. Motherhood practice which followed up and corrected by family physician going hand by hand with accurate infant growth and development monitoring is opportunity to save millions of infants from growth and development retardation ${ }^{(8)}$.

Aim: improvement of motherhood practice in order to improve child development.

\section{Objectives:}

1- Assessment of motherhood practice.

2- Assessment of childhood developments

3- Relate between motherhood practice and child growth and developments

\section{Subjects and Methods:}

Study design: observational cross section study.

Study sitting: Kafr Mohamed Ismail family medicine unit, Fakus health district Sharkia governorate.

Time frame: 6 month period from January 2017 to June 2017.

Sampling: sample size calculated by EPI6 calculator considering total infant population and expected prevalence, sample size was 140 infant and toddlers.

Inclusion criteria: infant from birth to 1 year and toddler from one year to 18 months.

Exclusion criteria: toddlers older than 18 months and infant with congenital anomalies or chronic diseases.

Data collection tool: designed questionnaire has two parts:
1-Basic socio-economic information and mother practice interview sheet.

2- Infant growth and development screening sheet based on standardized tool (ministry ofHealth growth and development screening tool ${ }^{(5)}$ Include the following measurements: Gross movements, fine movements, vision, hearing, talking, weight, height, hemoglobin, thyroid function test and social behavior.

Statistical analysis: data entry and analysis by SPSS 20 using Chi -squared test for $2 \times 2$ and $2 \times 3$ tables.

\section{Ethical consideration:}

Official approval from Fakus health district and family unit manager

Verbal consent obtained from mothers and fathers of all infants involved in the study and renewed every visit for child examination.

\section{Result}

$1^{\text {st }}$ figure shows that there is no significant difference between male and female in retardation percent.

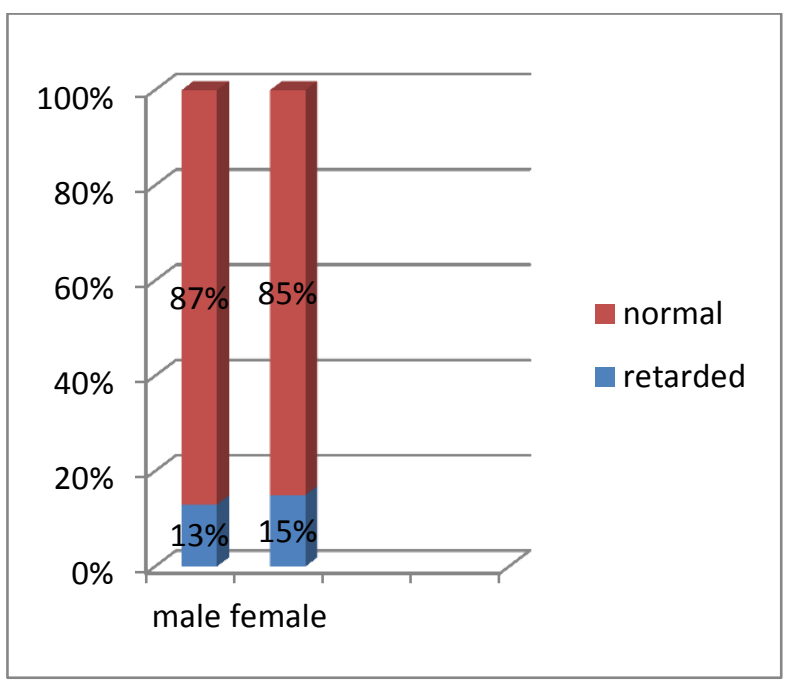

Figure 1: sex distribution of examined infants

Table 1 shows The socioeconomic status of the family based on the parents' education, work and income. Socioeconomic state has a significant effect on development. It was statistically significant. The illiteracy rate 
was among mothers $3.6 \%$ secondary education was completed by mothers $12.1 \%$ High education was completed by mothers76.4\% It could be noticed that mother's education was related to child development, when retardation reached high level among children whose caring mothers didn't reach the secondary level of education (high school).

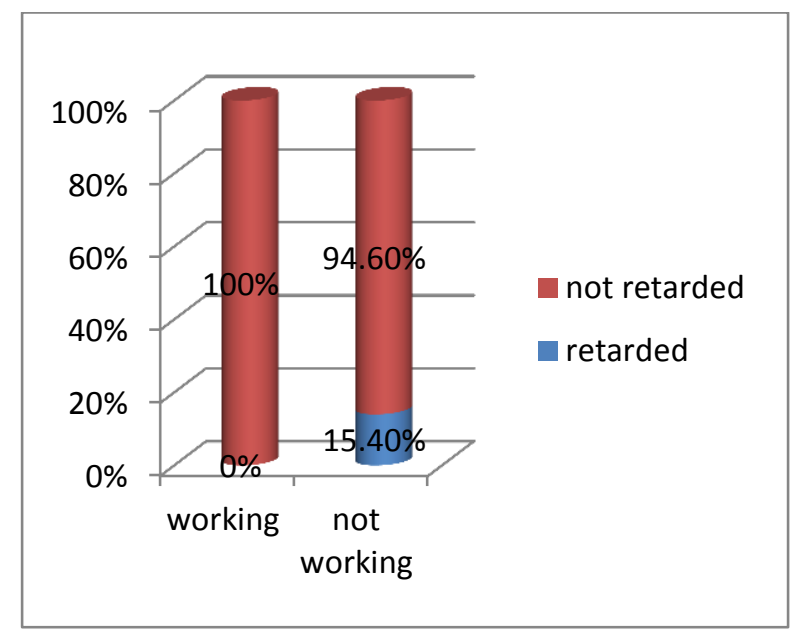

Figure 2: Relation between mother work and development.

Table 2 shows The mother rapid response to the crying child protects child from retardation, It was statistically significant . Responsive feeding is the interaction between mother and child during feeding showed an excellent result on development of the child. Forcing the child to eat was practically by 2 mothers only and show negative effect on child development. The worst was leaving them eating alone.

Table 1: Relation between socioeconomic state and mother education with different development:

\begin{tabular}{lllllll}
\hline Mothers characteristics & \multicolumn{2}{l}{ Retarded } & \multicolumn{2}{l}{ Not retarded } & Total & p \\
\cline { 2 - 3 } Social class & $\mathrm{N}$ & $\%$ & $\mathrm{~N}$ & $\%$ & & \\
Low & 5 & $100 \%$ & 0 & $0 \%$ & 5 & \\
Middle & 14 & $48.3 \%$ & 15 & $51.7 \%$ & 29 & 0.001 \\
High & 1 & $0.9 \%$ & 105 & $99.1 \%$ & 106 & \\
Mother education & & & & & & \\
Illiterate & 5 & $100 \%$ & 0 & $0 \%$ & 5 & 11 \\
Read \& write & 8 & $72.7 \%$ & 3 & $27.3 \%$ & 17 & 0.001 \\
Secondary & 5 & $29.4 \%$ & 12 & $70.6 \%$ & 17 & \\
High & 2 & $1.9 \%$ & 104 & $98.1 \%$ & 106 & \\
\hline
\end{tabular}

Figure 2 shows the percentage of retardation was $0.0 \%$ among working mothers, although the percentage of retardation was $15.4 \%$ among children of non-working mothers; the difference was not statically significant. 
Table 2: Relation between mother response to crying infant and mothers' behavior while feeding infants

\begin{tabular}{|c|c|c|c|c|c|c|}
\hline \multirow[t]{2}{*}{ Mothers behavior } & \multicolumn{2}{|l|}{ Retarded } & \multicolumn{2}{|c|}{ Not retarded } & \multirow[t]{2}{*}{ Total } & \multirow[t]{2}{*}{$\mathbf{p}$} \\
\hline & $\mathrm{N}$ & $\%$ & $\mathrm{~N}$ & $\%$ & & \\
\hline \multicolumn{7}{|l|}{ Response to crying } \\
\hline Repaid response & 3 & $2.6 \%$ & 112 & $97.4 \%$ & 115 & \multirow{3}{*}{0.001} \\
\hline Use pacifier & 2 & $33.3 \%$ & 4 & $66.7 \%$ & 6 & \\
\hline Ignore & 15 & $78.9 \%$ & 4 & $21.1 \%$ & 19 & \\
\hline \multicolumn{7}{|l|}{$\begin{array}{l}\text { Mother behavior } \\
\text { feeding }\end{array}$} \\
\hline Talk or sing & 1 & $1.3 \%$ & 74 & $99.7 \%$ & 75 & \multirow{4}{*}{0.001} \\
\hline Nominate food items & 3 & $6.5 \%$ & 43 & $93.5 \%$ & 46 & \\
\hline Force them on food & 1 & $50 \%$ & 1 & $50 \%$ & 2 & \\
\hline Leave them alone with food & 15 & $88.2 \%$ & 2 & $11.8 \%$ & 17 & \\
\hline
\end{tabular}

Table 3 shows that breast feeding in first six months of life was practiced by $92.9 \%$ of mothers. Retardation was more between those on formula. Breastfeeding was statistically significant.

Giving the child toys to play with, did show significant positive results. This was more evident with rubber toys, followed by cloth doll toys then build up toys.

Table 3: Relation between type of feeding, playing with toys and infant development:

\begin{tabular}{|c|c|c|c|c|c|c|}
\hline \multirow[t]{2}{*}{ Mothers feeding practice } & \multicolumn{2}{|c|}{ Retarded } & \multicolumn{2}{|c|}{ Not retarded } & \multirow[t]{2}{*}{ Total } & \multirow[t]{2}{*}{ p } \\
\hline & $\mathrm{N}$ & $\%$ & $\mathrm{~N}$ & $\%$ & & \\
\hline Breast feeding & 10 & $7.6 \%$ & 120 & $92.4 \%$ & 130 & \\
\hline Artificial feeding & 10 & $100 \%$ & 0 & $0 \%$ & 10 & 0.001 \\
\hline \multicolumn{7}{|c|}{$\begin{array}{l}\text { Playing with toys as daily } \\
\text { routine }\end{array}$} \\
\hline Playing & 16 & $12.4 \%$ & 114 & $87.6 \%$ & & \\
\hline Not playing & 4 & $40 \%$ & 6 & $60 \%$ & & 0.015 \\
\hline
\end{tabular}

\section{Discussion}

The study included 140children aged 18 months and less (68 males and 72 females ) as shown in figure $1,14.3 \%$ of the study sample were retarded in all domains. In general, retardation was more among females in all domains. This finding may raise the question about difference in rearing practice as regards male and female off spring.In a previous Egyptian study ${ }^{(\mathbf{9})}$,
Carried on less than 3 years children in a rural area males achieved better developmental milestone score more than females. Boys achieved higher score more than girls in all developmental domains, for example $41.8 \%$ in compared with $20.3 \%$ among males and females respectively in social development ${ }^{(9)}$. 
As shown in table 1: Family members provide most environmental stimuli for children, and families largely control a child's contact with distal environment. The most salient features of the family environment are its social and economic resources. Social resources Include parenting skills and education, cultural practices and approaches, interfamilial relations, and the health status of family members ${ }^{(10)}$.

education of both parents appears as a strong factor that affects the development. Thehigher the level of the mother education the less the retardation in all domains. It was statistically significant. The percent of retardation in infants whose mothers were highly educated were $1.9 \%$. The percent of retardation in infants whose mothers were illiterate were $100 \%$. The importance of mother education appears also in other studies as El Salamony ${ }^{(9)}$, and Augustineet $\boldsymbol{a l}{ }^{(11)}$. Research on this process focuses on three mechanisms. First, as women gain education, they are more likely to use complex language with their children, read with and provide home learning activities for their children, accompany their children on intellectual activities ${ }^{(9,10)}$.

Employment status of the mother gives her more knowledge about what is needed for their children to succeed in the long run. In our study mothers work was associated with no retardation. Results were statistically significant. However, contraindicated result was reported by El-Salammony ${ }^{(9)}$.

As shown in table NO.(2), The newborn communicates primarily by crying. At first crying is unintentional, simply a response to discomfort or need. But as the caregiver respond to the infant's cries, the baby learns to cry for specific reasons ${ }^{(12)}$. As a result, the child forms a

Greater attachment to his parents, develops trust more readily, and cries less. ${ }^{(13)}$. The response of the mother to the child cry is important factor in child development as we found in our study. The study show that quick response to the child cry give good feedback on child development(percent of retardation were2.6\%) while ignoring the child cry(percent of retardation were $78.9 \%$ ) or giving him pacifier (percent of retardation were $33.3 \%$ ) have negative effect on his development.

As shown in table NO.(2), Maternal interaction when feeding the child is also important factor in child development as we found in our study. The study show that feeding the child without interaction give negative feedback on his development(percent of retardation were88.2\%) while feeding the child with talking(percent of retardation were $1.3 \%$ ) or teaching him the types of food (responsive feeding) (percent of retardation were6.5\%) have good effect on his development. Feeding style refers to the interaction between caregiver and the children that occurs during meals. With gentle encouragement and responsive feeding, evidence shows that children will often eat more than if theyare left to eat on their own.In this study, responsive feeding has a good effect on child development. This is in agreement with Gergesetal. $^{(14) \text {. }}$

As shown in table NO.(3)In our study, exclusive breast feeding in first six months of life was practiced by92.9\% of mothers. Retardation was more betweenthose on formula. This findingis in agreement with Gergeset al. as the percent of retardation among infants on formula were $91.6 \%$ while $27.7 \%$ among breastfeeding ${ }^{(14) .}$

The central role of play in children's development is not always appreciated. Play processes influence synaptic formation and are linked to secure attachment with caregivers and relationships with other children. Play provides an important socializing function, beyond the merits of being physically active, in which children learn about and negotiate 
identity and the social subtleties of relationships. The effect of play also appears in others studies like Loriet al ${ }^{(4)}$.In our study we detected the importance of play and giving the child toys. The positive effect is evident more with giving the child rubber toys, cloth doll toys and build up toys. Percent of retardation in children who play with toys was $12.4 \%$. Percent of retardation in children who didn't play with toys was $40 \%$.This result is in agreement with Gerges et al., Percent of retardation in children who play with toys was39.6\%. Percent of retardation in children who didn't play with toys was $\% 61.4 \%{ }^{(14) .}$

\section{Reference}

1. WHO (2010) :fact for life $4^{\text {th }}$ edition ,published by UNICEF,www.WHO.org

2. Lisa Oakley (2004): Senior lecturer in psychology Manchester Metropolitan University; Cognitive development, published by Routledge USA; chapter 1 .

3. Daniel $B$ and Steven $\mathbf{P}(2003)$ : Paediatrics for medical students 2nd edition, published by Lippincott Williams \& Wilkins USA, chapter 12 .

4. Lori G, Arjumand $S$ and ClydeH (2007): Early child development www.who.int.ecd_kn_report.

5. Ministry of Health and Population (2007): Practice guidelines for family physician vol. 1 chapter 4. www.scribd.com

6. Lieberman A (1993): The Emotional Life of the Toddler. New York, Free Press, chapter 5 .
7. utter M (2002): From evangelism through science toward policy and practice. Child Dev .,73:1-21

8. Jurimae $\mathbf{J}$, Hills $A$ and Jurimae $\mathbf{T}$ (2010): Cytokines, growth mediators and physical activity in children during puberty. Library of congress cataloging, www.karger.com.website

9. El-Salamony O (1994): Maternal stimulation for promotion of development of children in the first 3 years of life. MD thesis, Faculty of medicine, Cairo University.

10. Roland $M$ and Nicholas $R($ 2009):. Infant mortality during economic downturns and recovery. social and economic policy working paper, chapter 2 .https//papers.ssrn.com

11. Jennifer $M$, Shannon $E$ and Robert $C$ (2009) :Maternal Education, Early Child Care and the Reproduction of. Advantage Published in final edited form as: Soc Forces, 88(1): 1-29. https://academic.oup.com

12. Jose B and Craig W(2010): Human behavior in the social environment. Library of congress, $4^{\text {th }}$ edition; chapter 7 , www.nla.gov.au

13. Whaley $L$ and Wong $D($ 1987):.Nursing care of infants and children 3rdedition, St. Louis. Mosby Company.

14. Gerges $Z$ (2011): Role of Family Physician in Detection of Risk Factors Affecting Early Childhood Development ,MD thesis ,faculty of medicine Cairo Univeristy. 